Published in final edited form as:

J Community Health. 2008 August ; 33(4): 217-224. doi:10.1007/s10900-008-9084-x.

\title{
Development Of An ESL Curriculum To Educate Chinese Immigrants About Hepatitis B
}

\author{
Victoria M. Taylor, MD, MPH, Gloria Coronado, PhD, and Elizabeth Acorda, MA \\ Cancer Prevention Program Fred Hutchinson Cancer Research Center 1100 Fairview Avenue North \\ (M3 - B232) Seattle, Washington 98109, USA email: vtaylor@fhcrc.org \\ Chong Teh, PhD, \\ Cancer Control Research Program British Columbia Cancer Agency 675 West Tenth Avenue \\ Vancouver, British Columbia V5Z 1L3, Canada
}

\section{Shin-Ping Tu, MD, MPH,} Department of Medicine Harborview Medical Center 325 Ninth Avenue Seattle, Washington 98104, USA

Yutaka Yasui, PhD, Department of Public Health Sciences University of Alberta (Clinical Sciences Building) Edmonton, Alberta T6G 2G3, Canada

Roshan Bastani, PhD, and Department of Health Services University of California Los Angeles 650 Charles Young Drive South Los Angeles, California 98005, USA

\section{T. Gregory Hislop, MDCM}

Cancer Control Research Program British Columbia Cancer Agency 675 West Tenth Avenue Vancouver, British Columbia V5Z 1L3, Canada

\section{Abstract}

Chinese immigrants to North America have substantially higher rates of chronic hepatitis B infection than the general population. One area for strategic development in the field of health education is the design and evaluation of English-as-a-Second language (ESL) curricula. The theoretical perspective of the Health Behavior Framework, results from a community-based survey of Chinese Canadian immigrants with limited English proficiency, and findings from focus groups of ESL instructors as well as Chinese ESL students were used to develop a hepatitis B ESL educational module. This research was conducted in Vancouver, British Columbia. Survey data showed that less than three-fifths of the respondents had been tested for hepatitis B, and documented some important hepatitis B knowledge deficits. Further, only about one-quarter had ever received a physician recommendation for hepatitis B serologic testing. The ESL curriculum aims to both promote hepatitis B testing and improve knowledge, and includes seven different ESL exercises: Warm-up, vocabulary cards, information-gap, video, jigsaw, guided discussion, and problem/advice cards. Our quantitative and qualitative methods for curriculum development could be replicated for other health education topics and in other limited English speaking populations.

\section{Keywords}

Chinese immigrants; English as a second language (ESL); Health education; Hepatitis B 


\section{Introduction}

Over the last 25 years, North America has experienced one of the largest immigration waves in history [1]. Asians are one of the fastest growing immigrant populations, and Chinese are the largest Asian sub-group in both Canada and the United States (US) [2]. Recent Census data indicate that approximately 1,100,000 Canadians are of Chinese descent. Nearly three-quarters of Chinese Canadians are foreign born, over one-half immigrated within the last 10 years, and over two-thirds speak a Chinese language at home [3]. Hepatitis B virus (HBV) infection is endemic in most Asian countries [4]. Therefore, it is not surprising that the rate of chronic hepatitis B infection among Chinese immigrants to North America is over ten times the general population rate of less than $0.5 \%[5,6]$.

Exposure to hepatitis B results in infection that can either be asymptomatic or present as acute hepatitis. While hepatitis B exposure among adults is usually followed by immunity, a proportion of those who are infected become carriers of the virus [7,8]. Carriers continue to be potentially infectious to others, and are at increased risk of chronic active hepatitis, cirrhosis, and liver cancer [6,8]. Chronically infected individuals may benefit from anti-viral therapy as well as regular screening for liver cancer, and should take precautions to avoid infecting others [6,8-10]. Therefore, authorities recommend that population sub-groups at high risk for chronic hepatitis B infection receive serologic testing for the disease [8].

In Asian countries, hepatitis B transmission usually occurs vertically from mother to child at birth [11]. However, horizontal transmission can also occur through sexual intercourse or close household contact (e.g., sharing razors) with a hepatitis B carrier [5]. Potential strategies for controlling hepatitis B among Asian populations include the routine testing of immigrants, vaccinating immigrants who have never been exposed to the virus (especially those who are at high risk of infection such as the family members of chronic carriers), and educating communities about the routes of hepatitis B transmission [12].

Adult basic education systems offer important opportunities for providing classes on health education about topics such as hepatitis B. Further, ESL instruction is an important component of adult basic education in North America. Canadian data indicate that a significant proportion of immigrants participate in ESL education, and ESL classes provide health educators with ready access to populations with limited English language proficiency $[13,14]$. In addition, the ESL environment is considered to be an ideal avenue for health education since people in ESL classes are generally motivated to improve their knowledge [15]. Finally, ESL classes allow participants to consider health information within the context of their daily life and in a "culturally safe" environment [16].

We were only able to identify one study that included a formal outcome evaluation of health education delivered during ESL classes. Elder and colleagues evaluated a cardiovascular disease nutrition educational program for Latino ESL students in San Diego, California [15]. Nutritional change materials were incorporated into the English language curriculum. Results showed long-term intervention effects on nutrition knowledge and fat avoidance, but only short term effects on cholesterol and systolic blood pressure.

There is very little literature addressing hepatitis B intervention programs for Asian immigrant communities or health education within the context of ESL classes. We conducted a hepatitis B needs assessment survey of Chinese living in Vancouver, British Columbia during 2005. This report provides quantitative data about the hepatitis B knowledge, health beliefs, and practices of limited English speaking Chinese immigrants (the sub-group that would benefit from ESL education). It also describes how the theoretical perspective of the Health Behavior Framework, our survey data, findings from focus groups of ESL instructors and Chinese 
Canadian ESL students, and input from community-based organizations were used to develop a hepatitis B educational module for use in ESL curricula [17].

\section{Research Setting}

Our research was conducted in the British Columbia lower mainland. According to the 2001 Canadian Census, 161,000 residents of Vancouver city are of Chinese descent (29\% of the total population). Additionally, several other cities in the lower mainland have sizeable Chinese communities. For example, Richmond has 64,000 Chinese residents (39\% of the total population) and Burnaby has 50,000 Chinese residents (26\% of the total population) [3]. British Columbia has a Provincial Medical Service Plan that provides health care at no cost (including hepatitis B testing, vaccination, and treatment), and residents of the Province generally have a primary care physician.

The Canadian English Language Services for Adults (ELSA) program offers free-of-charge ESL classes for limited English speaking immigrants [18]. As part of this program, each immigrant's English proficiency is assessed to decide whether he/she should start his/her English language education in ELSA level 1, ELSA level 2, or ELSA level 3 classes. For example, immigrants who speak very little or no English are initially placed in ELSA level 1 classes. As a student's English language proficiency improves, he/she progresses to a higher ELSA level. Three community-based organizations that provide ELSA classes in greater Vancouver participated in the reported research.

\section{Conceptual Framework}

We used the Health Behavior Framework as the conceptual model for our research. The Health Behavior Framework represents a synthesis of some of the major theoretical formulations in the area of adherence, including the Health Belief Model, the Theory of Reasoned Action/ Planned Behavior, components of PRECEDE, and social influence theory [17]. Unlike many other models, the Framework recognizes that factors affecting behavior may vary between population sub-groups and can be culturally determined. It specifies that constructs influencing an individual's health behavior include knowledge, health beliefs (e.g., perceptions regarding susceptibility to a health problem, the severity of a disease, and the effectiveness of a prescribed behavior), cultural beliefs, social norms/support, and communication with provider [17, 19-21]. Health Behavior Framework constructs have previously been shown to be associated with the hepatitis B testing behavior of Chinese and other Asian immigrant populations [22-24].

\section{Overview Of Curriculum Development}

Multiple methods were used to develop the content and format of our hepatitis B ESL curriculum for Chinese Canadian immigrants with limited English proficiency. Specifically, we used quantitative findings from a community-based survey of Chinese immigrants to British Columbia, qualitative findings from focus groups of ESL instructors who taught students of Chinese descent, qualitative findings from focus groups of Chinese immigrants who were enrolled in ESL classes, and input from a project planning group that included program managers from community-based organizations that serve Chinese Canadians. These methods are described in detail below.

\section{Community-based Survey}

We conducted a community-based survey of Chinese Canadians living in Vancouver during 2005. Individuals were eligible to participate if they were of Chinese descent (regardless of country of origin); aged $18-64$ years; and able to speak Cantonese, Mandarin, or English. 
Our survey methods have previously been described in detail [25]. Briefly, we developed a sampling frame by applying a previously validated list of common Chinese last names to an electronic version of the Vancouver telephone book [26]. Households were randomly selected from 10 postal codes with a high proportion of Chinese residents. The survey was administered face-to-face in participants' homes by trilingual (Cantonese, Mandarin, and English) interviewers. The survey instrument specifically addressed hepatitis B testing practices, hepatitis B knowledge and health beliefs, social support, and communication with provider.

Five hundred and fifty one individuals completed our community-based survey, and the response rate among reachable and eligible households was 59\%. To assess the hepatitis B educational needs of Chinese with limited English proficiency (i.e., those who would potentially attend ESL classes), we conducted an analysis among immigrant respondents who indicated they did not speak English well or at all (and excluded those who said they spoke English well or fluently). Our sample size for this analysis included the 333 respondents who met this criterion. The demographic characteristics of the study group were as follows: $42 \%$ were men, $35 \%$ were less than 45 years old, and $45 \%$ had less than 12 years of education. Only $57 \%$ reported previous hepatitis B serologic testing. Table 1 summarizes our survey findings for the Health Behavior Framework variables. Specifically, we present frequencies for participants' responses to the Health Behavior Framework survey items, and significant associations between the Framework items and previous hepatitis B testing. Table 2 gives examples of how our survey findings were applied to the curriculum development.

\section{Focus Groups}

Before developing our ESL curriculum, we conducted three focus groups of ESL instructors, and three focus groups of limited English speaking Chinese immigrants who were enrolled in ESL classes. All our focus group participants were recruited by the three collaborating community-based organizations. Two of the student focus groups were conducted in Mandarin and one was conducted in Cantonese. Participants were asked to provide their opinions about different methods of ESL education in general, and provide advice about the content of a hepatitis B ESL educational curriculum in particular. A total of 29 instructors and 27 students participated in the focus groups, and each focus group session included nine or ten individuals. Using a grounded theory approach, four members of the research team (who are experienced in qualitative methods) independently coded the focus group transcripts for thematic content, and then met to discuss and summarize the themes. Table 3 provides the focus group findings of particular relevance to curriculum development, and examples of how the participants' recommendations were incorporated into the hepatitis B curriculum.

\section{Planning Group}

We formed a planning group for the project that includes representatives from the collaborating community-based organizations and members of the research team. Several of the planning group members are of Chinese descent. During planning group meetings, cultural issues that could potentially impact the effectiveness of our hepatitis B ESL curriculum were discussed. As a result of these discussions, several Chinese cultural beliefs are addressed in the hepatitis B ESL curriculum. First, the lesson informs students that hepatitis B testing only involves a small amount of blood (some Chinese believe that blood tests deplete the body of energy and, therefore, can be harmful). Second, we included information about the positive family benefits of hepatitis B testing and vaccination (collectivism is an important part of Chinese culture). Third, two of the ESL exercises focus on interactions between physicians and patients (Chinese cultural beliefs about social hierarchy are associated with a high respect for physicians) $[27$, 28]. 


\section{Overview Of Hepatitis B Curriculum}

The community representatives on the planning group thought that it would be difficult to develop a hepatitis B educational module for students who speak little or no English (because hepatitis B is a relatively complicated health education topic). Therefore, we developed a curriculum for ELSA level 3 students (who have some English proficiency). Members of the research group (with experience conducting hepatitis B intervention research in Asian immigrant populations) and a project consultant (with considerable experience designing ESL lessons for use in British Columbia) developed the hepatitis B ESL educational module. A draft curriculum was pre-tested with three further focus groups of instructors and three further focus groups of Chinese ESL students. Input from the pre-testing focus group sessions was used to refine the individual ESL exercises. Planning group members reviewed and edited the final curriculum exercises to ensure the English level was appropriate for students at ELSA level 3 .

We aimed to develop an ESL curriculum that would both promote hepatitis B testing and improve knowledge about hepatitis B among Chinese immigrants. Our choice of ESL exercises was based on input from the focus group participants and planning group members (Table 3). The ESL curriculum is designed for a three-hour class and contains multiple commonly used types of ESL lesson exercises [18,29]. Specifically, there are seven different exercises: Warmup, vocabulary cards, information-gap, video, jigsaw, guided discussion, and problem/advice cards.

Our survey data, focus group findings, and planning group members guided the lesson content (Tables 2 and 3). The curriculum systematically addresses the following Health Behavior Framework constructs: Knowledge (about routes of hepatitis B transmission), health beliefs (about perceived susceptibility to hepatitis B infection, perceived severity of hepatitis B infection, and perceived effectiveness of hepatitis B testing), cultural beliefs (about the negative consequences of blood tests, the importance of actions that benefit family members, and the significance of physician advice), social norms/support (in relation to hepatitis B) and communication with provider (about hepatitis B testing).

\section{Curriculum Exercises}

ESL classes usually start with a warm-up activity and a review of key vocabulary that will be included in the lesson. To activate students' prior knowledge and encourage social support, the instructor writes "Hepatitis B" on the board and asks students to discuss what they know or do not know about hepatitis B with a partner. After a few minutes of discussion, the students are asked to share their ideas with the whole class. For the vocabulary card exercise, small groups of students are given two sets of 24 cards. They work together matching words or phrases with meanings or pictures. For example, in this curriculum, the phrase "high risk" is matched with the meaning "when a person is in more danger than other people" and the phrase "eating utensils" is matched with a drawing of chopsticks, a fork, and a spoon.

In the third exercise, the ESL students work in pairs to complete information-gap worksheets that both refer to the same story. One student in each pair receives worksheet A and the other receives worksheet B. Student A is missing some vocabulary from his/her story, and student $\mathrm{B}$ is missing other vocabulary. Students take turns reading, speaking, listening, and writing until they have filled in their stories. Then, they answer comprehension questions on the back of their worksheets. Finally, a review of the comprehension questions takes place as a whole class. As shown in Table 4, our information-gap story focuses on an immigrant named Peter who goes to his doctor for a check-up. The passage is designed to address knowledge, health beliefs, cultural beliefs, and communication with health care providers. 
A short video clip features an immigrant named John. The first scene depicts a doctor's visit to discuss hepatitis B and request hepatitis B testing (communication with provider). The conversation between John and his doctor addresses knowledge (e.g., hepatitis B can be spread during childbirth and unprotected sex), health beliefs (e.g., immigrants from certain countries are at high risk of hepatitis B, people with hepatitis B can be infected for life, and there is treatment for hepatitis B disease), and cultural beliefs (e.g., the hepatitis B test only involves a small amount of blood and hepatitis B testing is the best way to protect family members). The second scene depicts John going to the laboratory for a hepatitis B test, and shows the test is simple and only requires a small amount of blood.

When completing jigsaw exercises, the class members form four equal sized groups and each group receives one of four reading passages. They read their passage and review it with others who have the same text. Then, students are reformed into new groups of four with each student in the reformed group having a different text. The students take turns relaying the information in their text to their new partners who have comprehension questions for each section. Once all four students have taught their material, the students have covered all the texts. Finally, comprehension questions are reviewed as a class. The four jigsaw passages systematically address knowledge, health beliefs, and cultural beliefs. Two of these passages are provided in Table 4.

During the guided discussion exercise, the ESL instructor answers any remaining questions the students may have about hepatitis B, and emphasizes the following key points: Immigrants from many countries are at high risk of hepatitis B, people who are hepatitis B carriers may not know they are infected with the virus, and a blood test is the only way to find out if someone has hepatitis B. Visual aids are used to emphasize these key points (e.g., a map of the world showing areas with endemic hepatitis $B$ infection). In addition, the instructor encourages students who have been tested for hepatitis B to share their experiences (to establish social norms and provide social support to students who have not been tested).

Finally, small groups of students are given a set of six problem/advice cards. Each group of students discusses the problems or situations on the cards and offers advice. Then, the problems and advice are discussed as a class. The cards are designed to address knowledge and beliefs, as well as social support and norms (by encouraging students to discuss hepatitis B). For example, two of the problem/advice cards address concerns about blood tests (Mary is from Asia and all her friends had hepatitis B tests. She does not want to get tested because she is worried the test will take a large amount of blood. What would you tell Mary?) and hepatitis $B$ vaccination (Susan is getting married next year. Her boyfriend has hepatitis B. How can Susan make sure she does not get hepatitis B?).

\section{Discussion}

Our survey findings show that there is a continued need for health education programs addressing hepatitis B control among Chinese immigrants. Specifically, the data indicate that less than $60 \%$ of limited English speaking Chinese Canadians have been tested for hepatitis $\mathrm{B}$, and showed some important hepatitis B knowledge deficits. For example, only a minority of our community-based survey respondents knew that Chinese are more likely to be infected with hepatitis B than whites. In addition, our survey data indicate that physicians are not routinely recommending hepatitis B testing for foreign-born Chinese Canadians. Finally, our survey findings suggest that social norms/support and communication with provider are important constructs with respect to hepatitis B testing.

ELSA classes are currently provided by more than 15 community-based organizations at over 30 locations in the metropolitan Vancouver area. We are currently conducting a group- 
randomized controlled trial to evaluate the effectiveness of our curriculum in increasing hepatitis B testing rates and improving hepatitis B related knowledge. Free-of-charge ELSA level 3 classes provided by community-based organizations in British Columbia are being randomized to experimental or control status. Experimental group classes are receiving the hepatitis B educational ESL curriculum and control group classes are receiving a physical activity educational ESL curriculum. (At the request of our participating community-based organizations, students who have received a hepatitis B test are being included in the project.) Outcome ascertainment will be based on an in-person survey, conducted six months after attending a project ESL class, and medical records verification of self-reported hepatitis B testing. Each ESL class includes an average of 10 Chinese students and we will randomize 60 classes. Therefore, we anticipate that the experimental and control groups will each include 300 individuals. Our outcome evaluation will be the subject of a future report.

Authorities recommend the use of culturally appropriate conceptual frameworks, as well as qualitative and quantitative methods during the development of health educational programs for less acculturated immigrant groups [30-33]. This article describes the development of a hepatitis B ESL curriculum for Chinese immigrants to British Columbia. Our approach was conceptually grounded by the Health Behavior Framework and utilized community-based survey data, findings from focus groups of ESL instructors and students, and advice from community representatives. We believe our methods for intervention development could be replicated to develop ESL lessons addressing other health education topics (e.g., cancer screening) and for other limited English speaking populations in North America (e.g., Spanish speaking). Further, we believe that our hepatitis B curriculum could be used in other areas with large Chinese immigrant communities (e.g., New York, San Francisco, and Toronto).

\section{Acknowledgments}

The authors would like to thank the following British Columbia community-based organizations for their assistance with this project: Immigrant Services Society, Richmond Continuing Education, and S.U.C.C.E.S.S. In addition, we would like to thank Ming Berka, Flaury Bubel, Jill Collingwood, Michael Khoo, and Diana Smolic for recruiting focus group participants and reviewing the hepatitis B curriculum. We also thank Jennifer Walsh Marr for her invaluable assistance with curriculum development. Finally, we thank our survey and focus group participants. This work was supported by two grants and one cooperative agreement from the US National Cancer Institute: CA097199, CA113663, and CA114640.

\section{References}

1. Kandula N, Keresey M, Lurie N. Assuring the health of immigrants: What the leading health indicators tell us. Ann Rev Public Health 2004;25:357-376. [PubMed: 15015925]

2. US Department of Commerce. We the People: Asians in the United States-Census 2000 Special Reports. US Department of Commerce; Washington DC: 2004. p. 1-4.

3. Statistics Canada. Census. 2001. 2005. www.statcan.ca

4. Nguyen M, Keeffe E. Chronic hepatitis B and hepatitis C in Asian Americans. Rev Gastroenterol Dis 2003;3:125-134.

5. Asian Liver Center. Hepatitis B in Asian Americans. 2005. www.liver.stanford.edu

6. Tong M, Hwang S. Hepatitis B virus infection in Asian Americans. Gastroenterol Clin North Am 1994;23:523-536. [PubMed: 7989093]

7. di Bisceglie AM, Rustgi VK, Hoofnagle JH, Dusheiko GM, Lotze ML. NIH conference: Hepatocellular carcinoma. Ann Intern Med 1988;108:390-401. [PubMed: 2449110]

8. Lok A, McMahon B. Chronic hepatitis B. Hepatol 2001;34:1225-1241.

9. Lin OS, Keefle E. Current treatment strategies for chronic hepatitis B and C. Ann Rev Med 2001;52:29_ 49. [PubMed: 11160766]

10. Malik AH, Lee WM. Chronic hepatitis B virus infection: treatment strategies for the next millennium. Ann Intern Med 2000;132:723-731. [PubMed: 10787366] 
11. Merican I, Guan R, Amarapuka D, et al. Chronic hepatitis B virus infection in Asian countries. J Gastroenterol Hepatol 2000;15:1356-1361. [PubMed: 11197043]

12. Jenkins CNH, Buu C, Berger W, Son DT. Liver carcinoma prevention among Asian Pacific Islanders. Cancer (Suppl) 2001;91:252-256.

13. Edwards N, Silisha D, Halbert T, Pond M. Health promotion and health advocacy for and by immigrants in English as a Second Language classes. Can J Public Health 1992;83:159-162. [PubMed: 1617560]

14. Massachusetts Department of Education. Why teach health: the adult basic education curriculum framework for health. 2004. www.worled.org/us/health

15. Elder JP, Candelaria JI, Woodruff SI, Criqui MH, Talavera GA, Rupp JW. Results of language for health: cardiovascular disease nutrition education for Latino English-as-a-second-language students. Health Educ Behav 2000;27:50-63. [PubMed: 10709792]

16. Hohn, M. Empowerment health education in health literacy. National Institute for Literacy; Washington DC: 1998. p. 1-3.

17. Curry SJ, Emmons KM. Theoretical models for predicting and improving compliance with breast cancer screening. Ann Behav Med 1994;16:302-316.

18. ELSA Net. Newcomber's guide educational resource. 2006. www.elsanet.org

19. Bastani R, Maxwell AE, Bradford C, Das IP, Yan KX. Tailored risk notification for women with a family history of breast cancer. Prev Med 1999;29:355-364. [PubMed: 10564627]

20. Gritz ER, Bastani R. Cancer prevention-behavior changes: the short and long of it. Prev Med 1993;22:676-688. [PubMed: 8234207]

21. Maxwell AE, Bastani R, Vida P, Warda US. Results of a randomized trial to increase breast and cervical cancer screening among Filipino American women. Prev Med 2003;37:102-109. [PubMed: 12855209]

22. Bastani R, Glenn B, Maxwell A, Jo A. Liver cancer prevention among Korean Americans. Ethnic Dis 2007; 17:365-373.

23. Taylor V, Tu S, Woodall E, et al. Hepatitis B knowledge and practices among Chinese immigrants to the United States. Asian Pacific J Cancer Prev 2006;7:313-317.

24. Taylor VM, Yasui Y, Burke N, et al. Hepatitis B testing among Vietnamese American men. Cancer Det Prev 2004;28:170-177.

25. Hislop T, Tah C, Low A, et al. Hepatitis B testing and vaccination levels in Chinese immigrants to British Columbia. Can J Public Health 2007;898:125-129. [PubMed: 17441536]

26. Lauderdale DS, Kestenbaum B. Asian American ethnic identification by surname. Population Res Policy Rev 2000;19:283-300.

27. Tu SP, Chen H, Chen A, Lim J, May S, Drescher C. Clinical trials: understanding and perceptions of female Chinese American cancer patients. Cancer 2005;104:2999-3005. [PubMed: 16247796]

28. Park, Y. The Chinese Community in the United States. Cross Cultural Health Care Program; Seattle: 1999. p. 15-18.

29. Podnecky, J.; Grognet, AG.; Crandall, J. Life prints: ESL for adults. New Readers Press; New York: 2002. p. 20-26.

30. de Vries H, Weijts W, Dijkstra M, Kok G. The utilization of qualitative and quantitative data for health education program planning, implementation, and evaluation: a spiral approach. Health Educ Quart (Suppl) 1992;19:101-115.

31. Farquhar SA, Parker EA, Schulz AJ, Israel BA. Application of qualitative methods in program planning for health promotion interventions. Health Prom Pract 2006;7:234-242.

32. National Cancer Institute. Theory at a glance: A guide for health promotion practice. US Department of Health and Human Services; Washington DC: 2005. p. 3-7.

33. Steckler A, McLeroy KR, Goodman RM, Bird TL, McCormick L. Toward integrating qualitative and quantitative methods: an introduction. Health Educ Quart (Suppl) 1992;19:1-8. 
Community-based survey findings $(\mathrm{N}=333)$
Table 1

\begin{tabular}{|c|c|c|}
\hline Variable & $\begin{array}{c}\text { Proportion of } \\
\text { respondents }(\%)\end{array}$ & $\begin{array}{c}\text { p-value for } \\
\text { association with } \\
\text { hepatitis B testing }\end{array}$ \\
\hline \multicolumn{3}{|l|}{ Knowledge } \\
\hline Knew HBV can not be spread by eating food prepared by an infected person & 20 & 0.005 \\
\hline Knew HBV can not be spread by sharing eating utensils & 8 & 0.01 \\
\hline Knew HBV can be spread during sexual intercourse & 63 & NS \\
\hline Knew HBV can be spread during childbirth & 71 & 0.06 \\
\hline Knew HBV can be spread by sharing razors & 67 & 0.03 \\
\hline \multicolumn{3}{|l|}{ Health beliefs } \\
\hline Believed Chinese are more likely to be infected with HBV than Whites & 41 & NS \\
\hline Believed HBV can be spread by someone who looks healthy & 78 & NS \\
\hline Believed people with HBV disease can be infected for life & 38 & 0.006 \\
\hline Believed HBV disease can cause liver cancer & 84 & NS \\
\hline Believed there are medicines to treat HBV disease & 59 & NS \\
\hline \multicolumn{3}{|l|}{ Social norms/support } \\
\hline Family member had suggested HBV testing & 18 & $<0.001$ \\
\hline Friend had suggested HBV testing & 9 & $<0.001$ \\
\hline \multicolumn{3}{|l|}{ Communication with provider } \\
\hline Doctor had recommended HBV testing & 24 & $<0.001$ \\
\hline Had asked doctor for HBV testing & 35 & $<0.001$ \\
\hline
\end{tabular}

* Statistical significance was assessed with chi-square tests and Fisher's Exact tests, when necessary - A p-value of less than 0.05 indicates the variable was associated with an increased level of hepatitis B testing - NS indicates no significant difference 
Table 2

Examples of application of survey findings to curriculum development

Findings

Application

\section{Knowledge}

- Very few respondents knew that hepatitis B can not be spread by eating food that has been prepared by an infected person and sharing eating utensils.

- Less than three-quarters of the respondents knew that hepatitis B can be spread during sexual intercourse, during childbirth, and by sharing razors.

- Levels of knowledge about hepatitis B transmission were associated with previous hepatitis B testing.

\section{Health beliefs}

- Only about two-fifths of the respondents knew that Chinese are more likely to be infected with hepatitis B than whites.

\section{Social norms/support}

- Social norms/support survey items were strongly associated with previous hepatitis B testing.

\section{Communication with provider}

- Over three-quarters of the respondents had never received a physician recommendation for hepatitis $\mathrm{B}$ testing.

- Communication with provider survey items were strongly associated with previous hepatitis B testing.
- The information-gap, video, and jigsaw exercises address established routes of hepatitis B transmission, and emphasize that hepatitis B can not be spread during meals.

- The video and jigsaw exercises provide information on areas of the world with endemic hepatitis B.

- During the guided discussion exercise, the instructor uses a world map to show geographic areas with high hepatitis $\mathrm{B}$ rates.

- The warm-up, guided discussion, and problem/advice card exercises are designed to encourage student interactions and address social norms/support in relation to hepatitis B.

- The information-gap exercise focuses on a doctor's visit to discuss hepatitis B.

- The video exercise role models a doctor's visit to request hepatitis B testing. 
Table 3

Examples of application of focus group findings to curriculum development

\begin{tabular}{ll}
\hline Findings & Application
\end{tabular}

\section{Curriculum format}

- Instructors favored exercises that encourage interactions between students.

- Instructors and students thought audiovisual presentations and visual aids are particularly useful.

\section{Curriculum content}

- Instructors recommended that we include information about the routes of hepatitis B transmission, methods of preventing hepatitis B infection, and the possible results of hepatitis B testing.

- Students recommended that we emphasize the severity of hepatitis B disease, explain how carriers can protect their family members from hepatitis B and improve their own health, and show students how to get a hepatitis B test.

Other

- Instructors and students believed it is important not to "stigmatize" Chinese as having high hepatitis B rates.
- The curriculum includes interactive information-gap and jigsaw exercises.

- A video was developed and visual aids are used during the guided discussion exercise.

- Routes of hepatitis B transmission, the consequences of hepatitis $B$ infection, hepatitis B vaccination, and the management of chronic hepatitis B disease are described in multiple exercises.

- The possible results of hepatitis B testing are given in the jigsaw and video exercises.

- "Canadian" rather than Chinese names are used in the information-gap, video, and problem/advice card exercises.

- The curriculum provides information about all regions of the world with high hepatitis B rates (rather than focusing on east Asia). 
Table 4

Content of ESL exercises

\section{Information-gap exercise passage *}

Peter is an immigrant. He goes to his doctor for a check-up. The doctor tells Peter that immigrants from his country should be tested for hepatitis B. The doctor recommends a hepatitis B blood test. Peter is worried the blood test will take too much blood. The doctor tells him it will be just a small amount.

The blood test shows that Peter has the hepatitis B virus in his blood. This means he is a hepatitis B carrier. Peter is worried he may pass the disease to his family and friends. The doctor explains that hepatitis B can't spread through everyday contact with people. Holding hands and sharing eating utensils do not spread hepatitis B. Sharing personal items such as toothbrushes, razors, and nail clippers can spread hepatitis B. Unprotected sex is high risk.

The hepatitis B virus will stay in Peter's body for life. He may get cirrhosis and liver cancer. He should get regular checkups, blood tests, and X-rays. Peter's doctor may give him medicine to prevent liver damage.

Peter's family should get tested for hepatitis B. If they do not carry the virus, they can get a vaccine for hepatitis B so they won't get infected.

\section{Examples of jigsaw exercise passages}

Anyone can get hepatitis B. Countries in Asia, Africa, the Middle East, Eastern Europe, and the former Soviet Union have high hepatitis B infection rates. Many immigrants come to Canada already infected with hepatitis B. They may be carriers but not know it. Most carriers have no symptoms and feel healthy. Moving to Canada does not change the risk of having the disease or of spreading it to family members.

A blood test can show if someone has hepatitis B. The blood test is simple. It only takes a couple of minutes and can be done in a doctor's office or at a lab. The nurse takes about $10 \mathrm{ml}$. of blood and the blood is checked for hepatitis B. Results are usually available in a couple of weeks. The blood test will tell the doctor if you have never been infected with hepatitis B, if you are immune to hepatitis B, or if you are a hepatitis B carrier.

* Words in the first and third paragraphs are missing from student worksheet A, and words in the second and fourth paragraphs are missing from student worksheet B. 